\title{
Analysis of chemokine and chemokine receptor expression in squamous cell carcinoma of the head and neck (SCCHN) cell lines
}

\author{
Hendrik A. Wolff • David Rolke • Margret Rave-Fränk • Markus Schirmer • \\ Wolfgang Eicheler $\cdot$ Annegret Doerfler $\cdot$ Andrea Hille $\cdot$ Clemens F. Hess $\cdot$ \\ Christoph Matthias · Ralph M. W. Rödel · Hans Christiansen
}

Received: 16 April 2010 / Accepted: 1 November 2010 / Published online: 18 November 2010

(C) The Author(s) 2010. This article is published with open access at Springerlink.com

\begin{abstract}
The purpose of this work was to analyze chemokine and chemokine receptor expression in untreated and in irradiated squamous cell carcinoma of the head and neck (SCCHN) tumor cell lines, aiming at the establishment of assays to test for the relevance of chemokine and chemokine receptor expression in the response of SCCHN to radiotherapy and radiochemotherapy. Five low passage and 10 established SCCHN lines, as well as two normal cell lines, were irradiated at 2 Gy or sham-irradiated, and harvested between 1 and $48 \mathrm{~h}$ after treatment. For chemokines with CC and CXC structural motifs and their receptors, transcript levels of target and reference genes were quantified relatively by real-time PCR. In addition, CXCL1 and CXCL12 protein expression was analyzed by ELISA.
\end{abstract}

H. A. Wolff and D. Rolke share the first authorship equally.

R. M. W. Rödel and H. Christiansen share the last authorship equally.

H. A. Wolff · D. Rolke · M. Rave-Fränk $(\bowtie) \cdot$ A. Hille ·

C. F. Hess $\cdot$ H. Christiansen

Department of Radiotherapy and Radiation Oncology,

Universitätsmedizin Göttingen, Göttingen, Germany

e-mail:mfraenk@med.uni-goettingen.de

M. Schirmer

Department of Pharmacology,

Universitätsmedizin Göttingen, Göttingen, Germany

C. Matthias · R. M. W. Rödel

Department of Otorhinolaryngology-Head and Neck Surgery,

Universitätsmedizin Göttingen, Göttingen, Germany

W. Eicheler · A. Doerfler

Department of Radiation Oncology,

OncoRay-Center for Radiation Research in Oncology,

Medical Faculty Carl Gustav Carus,

Technische Universität Dresden, Dresden, Germany
A substantial variation in chemokine and chemokine receptor expression between SCCHN was detected. Practically, all cell lines expressed CCL5 and CCL20, while CCL2 was expressed in normal cells and in some of the tumor cell lines. CXCL1, CXCL2, CXCL3, CXCL10, and CXCL11 were expressed in the vast majority of the cell lines, while the expression of CXCL9 and CXCL12 was restricted to fibroblasts and few tumor cell lines. None of the analyzed cell lines expressed the chemokines CCL3, CCL4, or CCL19. Of the receptors, transcript expression of CCR1, CCR2, CCR3, CCR5, CCR7, CCXR2, and CCXR3 was not detected, and CCR6, CXCR1, and CXCR4 expression was restricted to few tumor cells. Radiation caused up- and down-regulation with respect to chemokine expressions, while for chemokine receptor expressions down-regulations were prevailing. CXCL1 and CXCL12 protein expression corresponded well with the mRNA expression. We conclude that the substantial variation in chemokine and chemokine receptor expression between SCCHN offer opportunities for the establishment of assays to test for the relevance of chemokine and chemokine receptor expression in the response of SCCHN to radiotherapy and radiochemotherapy.

\section{Introduction}

Tumors are embedded in a rich cell microenvironment, which is essential for tumor cell survival, cancer progression, and metastasis. However, the means by which tumor cells interact with their surrounding are mostly unknown.

Chemokine molecules constitute a superfamily of often inducible, secreted, proinflammatory proteins involved in a variety of immune responses, acting primarily as chemoattractants and activators of specific types of leukocytes. 
They are typically induced by inflammatory cytokines, growth factors, and pathogenic stimuli and signal through transmembrane G-protein-coupled (chemokine) receptors. Chemokines are made and secreted by many different cell types, including tumor cells, tumor stroma cells, and tumorinfiltrating immune cells (Zlotnik 2006). Recent studies have shown the involvement of chemokine signaling in cancer treatment response and metastasis through autocrine and paracrine mechanisms (Wang et al. 2009; Zlotnik 2006).

Radiotherapy is an established treatment option for numerous tumors, and evidence is accumulating that radiation has considerable effects on chemokine expression (Ao et al. 2009; Facoetti et al. 2009; Gremy et al. 2008; Johnston et al. 2002; im et al. 2009; Kuhlmann et al. 2009; Linard et al. 2004; Lugade et al. 2008; Matsumura et al. 2008; Mihaescu et al. 2010; Moriconi et al. 2008; Muller and Meineke 2007; Sanzari et al. 2009; Schmidtner et al. 2009), while radiation effects on chemokine receptor expression are poorly investigated (Johnston et al. 2002; Malik et al. 2010). Experimental studies analyzed normal cells (Facoetti et al. 2009; Kuhlmann et al. 2009; Moriconi et al. 2008; Muller and Meineke 2007) or tissues (Ao et al. 2009; Gremy et al. 2008; Johnston et al. 2002; Linard et al. 2004; Malik et al. 2010; Mihaescu et al. 2010; Moriconi et al. 2008), as well as tumor cells of different origin (Kim et al. 2009; Lugade et al. 2008; Matsumura et al. 2008; Sanzari et al. 2009; Schmidtner et al. 2009).

Squamous cell carcinoma of the head and neck (SCCHN) has been shown to express a number of chemokines, and their receptors, which may e.g., promote chemotherapy resistance (Muller et al. 2006; Wang et al. 2008) or may allow them to access the lymphatic system and spread to regional lymph nodes (Samara et al. 2004; Ueda et al. 2009; Wang et al. 2004, 2005a, b). Schmidtner et al. reported on radiation-associated escalation of the chemo- kine CCL22 in SCCHN tumor cell supernatants, which might modify the transmigration of tumor-infiltrating lymphocytes beneficially and thereby support the immune response (Schmidtner et al. 2009).

We are aiming at the establishment of assays to test for the relevance of chemokine and chemokine receptor expression in the response of SCCHN to radiotherapy and radiochemotherapy. While searching the literature, we found that there are practically no published data on chemokine and chemokine receptor expression in commercially available SCCHN tumor cell lines. Therefore, we analyzed the transcript expression of 24 genes (Table 1), involving chemokines and chemokine receptors in 15 SCCHN and 2 normal cell lines; for validation, extracts pooled from cells with known or putative chemokine and chemokine receptor expression were analyzed as well.

The analyzed genes were selected with respect to our experiences concerning radiation-dependent cytokine/chemokine regulation (Malik et al. 2010; Moriconi et al. 2008) and with respect to published reports on chemokine expression in head and neck cancer (Abiko et al. 2003; Almofti et al. 2004; Chakraborty et al. 2008; Chang et al. 2008; Delilbasi et al. 2004; Ferreira et al. 2008; Ishikawa et al. 2006; Khademi et al. 2008; Michiels et al. 2009; Miyazaki et al. 2006; Muller et al. 2006; Oliveira-Neto et al. 2008; Rehman and Wang 2008; Takes et al. 2008; Tan et al. 2008; Tsuzuki et al. 2006; Ueda et al. 2009; Wang et al. 2005, 2008; Wen et al. 2008; Yeudall and Miyazaki 2007).

\section{Materials and methods}

The SCCHN cell lines used were either established from tumor material and used at low passage numbers (Rave-Frank et al. 1996) or commercially available (established cell lines)
Table 1 Chemokines and chemokine receptors of which the transcript expression was analyzed

\begin{tabular}{llll}
\hline Chemokine & Other names & Full name & Receptor \\
\hline CCL2 & MCP-1, SCYA-2 & Monocyte chemoattractant protein 1 & CCR2 \\
CCL3 & MIP-1 $\alpha$, SCYA3 & Macrophage inflammatory protein 1 alpha & CCR1, 5 \\
CCL4 & MIP-1 $\beta$, SCYA4 & Macrophage inflammatory protein 1 beta & CCR5, 8 \\
CCL5 & RANTES & Regulated upon activation of normal T cell & CCR1, 3, 5 \\
CCL19 & MIP3- $\beta$, SCYA19 & Macrophage inflammatory protein 3 beta & CCR7 \\
CCL20 & MIP3- $\alpha$, LARC & Macrophage inflammatory protein 3 alpha & CCR6 \\
CXCL1 & GRO $\alpha$, SCYB1 & Growth-related oncogene alpha & CXCR1, \\
CXCL2 & GRO $\beta$, SCYB2 & Growth-related oncogene beta & CXCR1, \\
CXCL3 & GRO $\gamma$, SCYB3 & Growth-related oncogene gamma & CXCR1, \\
CXCL9 & MIG, SCYB9 & Monokine induced by interferon gamma & CXCR3 \\
CXCL10 & IP-10, SCYB10 & Interferon-inducible protein-10 kilodaltons & CXCR3 \\
CXCL11 & I-TAC, SCYB9B & Interferon-inducible T-cell alpha chemoattractant & CXCR3 \\
CXCL12 & SDF-1, SCYB12 & Stromal cell-derived factor 1 & CXCR4 \\
\hline
\end{tabular}


Table 2 Origin and names of the used cell lines

\begin{tabular}{|c|c|c|c|}
\hline Cell line & Obtained from & Medium & Origin \\
\hline BHY & $\mathrm{DSMZ}^{\mathrm{a}}$ & DMEM & SCC (lower alveolus) \\
\hline XF 354 & $\mathrm{DKFZ}^{\mathrm{b}}$ & DMEM & $\mathrm{SCC}\left(\right.$ oral, $\left.\mathrm{M}^{\mathrm{f}}\right)$ \\
\hline CAL33 & $\mathrm{DSMZ}^{\mathrm{a}}$ & DMEM & SCC (tongue) \\
\hline SAS & HSRRB $^{\mathrm{c}}$ & DMEM + HAMsF12 1:1 & SCC (tongue) \\
\hline CAL 27 & $\mathrm{DSMZ}^{\mathrm{a}}$ & DMEM & SCC (tongue) \\
\hline HSC4 & HSRRB $^{\mathrm{c}}$ & MEM & SCC (tongue) \\
\hline HO 1u1 & HSRRB $^{\mathrm{c}}$ & DMEM + HAMsF12 1:1 & SCC (mouth floor) \\
\hline SKN3 & HSRRB $^{c}$ & RPMI & SCC (oral cavity) \\
\hline KOSC2 & $\mathrm{HSRRB}^{\mathrm{c}}$ & RPMI & SSC (oral floor) \\
\hline $\mathrm{FaDu}$ & RT-Dresden $^{\mathrm{d}}$ & DMEM & SCC (pharyngeal) \\
\hline ZMK-1 & RT-Göttingen ${ }^{\mathrm{e}}$ & DMEM + HAMsF12 1:1 & SCC (Oropharynx) \\
\hline BW-225 & RT-Göttingen ${ }^{\mathrm{e}}$ & DMEM + HAMsF12 1:1 & SCC (Oropharynx) \\
\hline HK-147 & RT-Göttingen ${ }^{\mathrm{e}}$ & DMEM + HAMsF12 1:1 & SCC (Oropharynx) \\
\hline GR-145-I & RT-Göttingen ${ }^{\mathrm{e}}$ & DMEM + HAMsF12 1:1 & SCC (Oropharynx) \\
\hline GR-145-II & RT-Göttingen ${ }^{\mathrm{e}}$ & DMEM + HAMsF12 1:1 & SCC (Oropharynx) \\
\hline DF-19 & RT-Göttingen ${ }^{\mathrm{e}}$ & DMEM & Dermal fibroblasts \\
\hline HaCat & $\mathrm{DKFZ}^{\mathrm{b}}$ & DMEM & Epidermal keratinocytes \\
\hline \multicolumn{4}{|c|}{${ }^{a}$ Deutsche Sammlung von Mikroorganismen und Zellkulturen GmbH, Braunschweig, Germany } \\
\hline \multicolumn{4}{|c|}{ b Deutsches Krebsforschungszentrum, Heidelberg, Germany } \\
\hline \multicolumn{4}{|c|}{${ }^{\mathrm{c}}$ Health Science Research Resources Bank, Japan Health Sciences Foundation, Japan } \\
\hline \multicolumn{4}{|c|}{$\begin{array}{l}\text { d Department of Radiation Oncology, OncoRay-Center for Radiation Research in Oncology, Medical Faculty Carl Gustav Carus, Technische Uni- } \\
\text { versität Dresden, Germany }\end{array}$} \\
\hline \multicolumn{4}{|c|}{ e Universitätsmedizin Göttingen, Department of Radiotherapy and Radiation Oncology, Göttingen, Germany } \\
\hline \multicolumn{4}{|c|}{${ }^{\mathrm{f}}$ Lymphnode metatasis } \\
\hline
\end{tabular}

(Table 2). For experiments, cells were grown in their recommended media (Table 2), irradiated at 2 Gy or shamirradiated, and harvested 6, 24, or $48 \mathrm{~h}$ upon treatment. Cell pellets and cell supernatants were stored at $-80^{\circ} \mathrm{C}$. For real-time PCR, cells were washed in PBS and stored at $-80^{\circ} \mathrm{C}$ in lysis buffer contained in RNeasy mini kit (Qiagen, Hilden, Germany). Total cell amount per sample was about 1 million cells. RNA was isolated using Rneasy mini kit according to the manufacturer's instructions. The amount of RNA was meticulously quantified by a spectrophotometric method specifically designed for precise measurements of undiluted samples in low microliter scale (LabelGuard cuvette; Implen, Munich, Germany). Reverse transcription to complementary DNA was effected for $1 \mathrm{~h}$ with $1 \mu \mathrm{g}$ total RNA using Super-Script II reverse transcriptase (Invitrogen, Carlsbad, California, USA) and 20 units per sample recombinant RNase inhibitor (USB, Cleveland, Ohio, USA). Transcript numbers of target and reference genes were quantified relatively by real-time PCR using HotStart-IT SYBR Green qPCR-Master Mix (USB, Cleveland, Ohio, USA) in a real-time PCR machine (HT7900, Applied Biosystems, Foster City, California, USA). PCR conditions were 40-50 cycles (dependent on expression level) with annealing at $60^{\circ} \mathrm{C}$ for $20 \mathrm{~s}$ and elongation at $72^{\circ} \mathrm{C}$ for $40 \mathrm{~s}$ for each primer pair. Specific primer pairs were synthesized by MWG, Ebersberg, Germany. Efficacy and specificity of primers were tested by serial dilution (factor 625). Primer sequences are given in Table 3. Data were normalized to weighted mean expression of HPRT1 and UBC serving as reference genes. The analysis was performed for cells harvested $6 \mathrm{~h}$ after treatment and shamtreated cells, respectively. Greater than twofold changes in transcript expression were taken as significant.

The amount of CXCL1 or CXCL12 protein was determined in cell culture supernatants by the Quantikine ${ }^{\circledR}$ Human CXCL1 or CXCL12 Immunoassays, R\&D Systems, Minneapolis, USA, according to recommended protocols. For experiments, tumor cells, HaCat-keratinocytes, or fibroblasts $\left(1,000.000\right.$ cells/flask) were seeded in $25-\mathrm{cm}^{2}$ flasks (Nalge Nunc Int., Rochester, NY) in their specific medium and allowed to attach. For measurement, supernatants collected either $0 \mathrm{~h}$ (control), 6, 24, or $48 \mathrm{~h}$ after (sham-)irradiation, and particulates were removed by centrifugation. Measurements were repeated 3 times, and the statistical significance of increased chemokine concentrations was tested by ANOVA. 


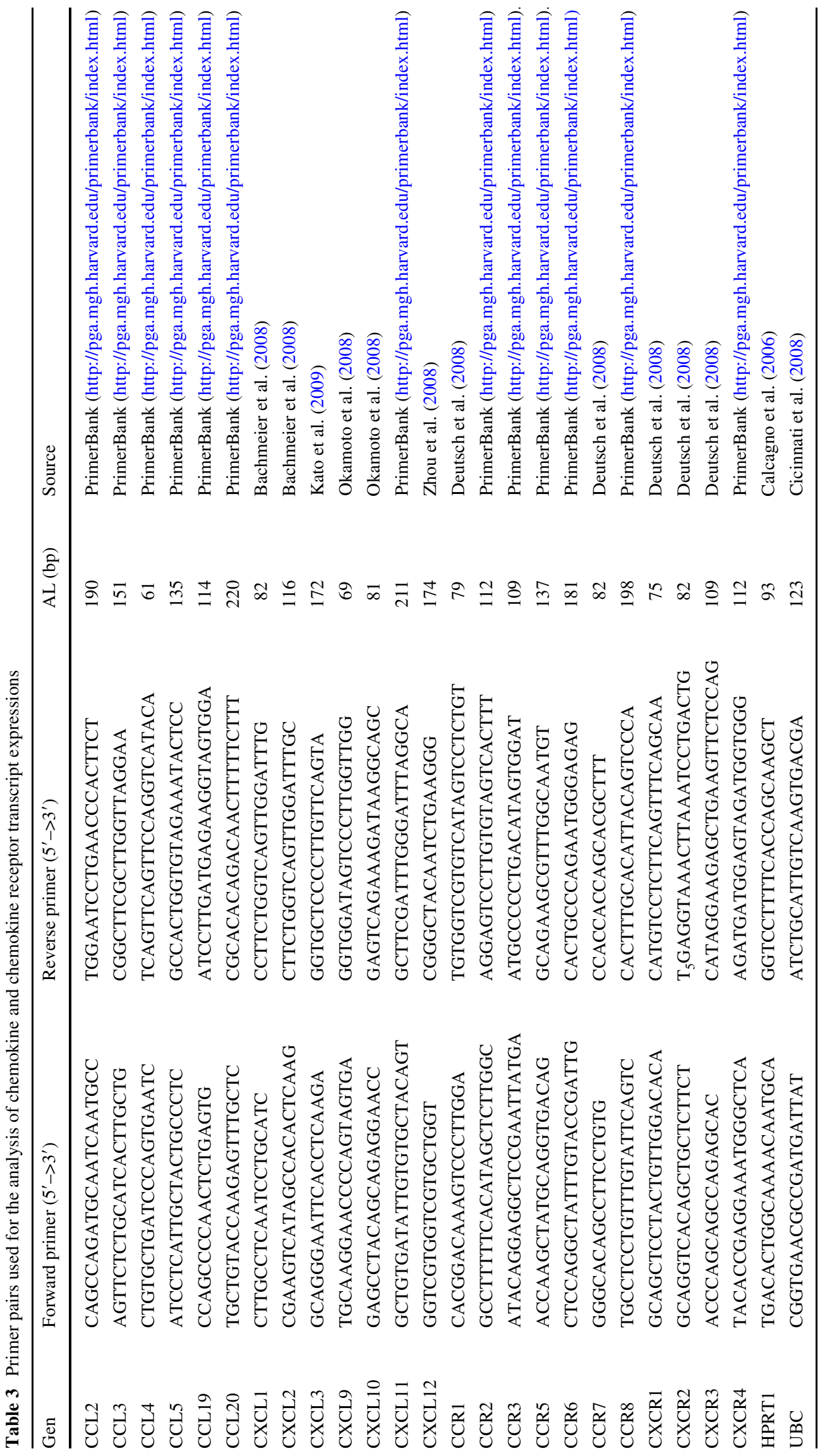


Table 4 Transcript expression of chemokines and chemokine receptors in the pooled sample

\begin{tabular}{llll}
\hline Chemokine & $\mathrm{C}_{\mathrm{T}}$ & Chemokine receptor & $\mathrm{C}_{\mathrm{T}}$ \\
\hline CCL2 & 20,33 & CCR1 & 30,80 \\
CCL3 & 26,08 & CCR2 & 29,07 \\
CCL4 & 29,67 & CCR3 & 28,58 \\
CCL5 & 26,43 & CCR5 & 29,44 \\
CCL19 & 30,15 & CCR6 & 22,77 \\
CCL20 & 18,07 & CCR7 & 30,12 \\
CXCL1 & 19,06 & CCR8 & 29,44 \\
CXCL2 & 19,89 & CXCR1 & 29,85 \\
CXCL3 & 20,58 & CXCR2 & 31,79 \\
CXCL9 & 29,66 & CXCR3 & 27,18 \\
CXCL10 & 26,91 & CXCR4 & 24,84 \\
CXCL11 & 25,99 & & \\
CXCL12 & 30,03 & & \\
\hline
\end{tabular}

\section{Results}

Within the pooled validation samples consisting of extracts from human lymphocytes, colorectal, and hepatocellular cancer cells, significant transcript expression of all analyzed chemokines and chemokine receptors was detected; the respective CT-values are given in Table 4.

Normal cells, as represented by dermal fibroblasts and HaCat-keratinocytes, showed comparable expression patterns, namely the expression of a variety of chemokines and no chemokine receptors. The transcript expression data for normal cells are integrated in Figs. 1, 2, 3, 4.

Practically, all cell lines expressed the CC-chemokines CCL5 and CCL20, while CCL2 was expressed in normal cells and in some of the tumor cell lines (BHY, CAL27, CAL33, HSC4, SAS, BW-225, ZMK-1) (Fig. 1a-c). Likewise, the CXC-chemokines CXCL1, CXCL2, CXCL3, CXCL10, and CXCL11 were expressed in the vast majority of the cell lines, while the expression of CXCL9 and CXCL12 was restricted to fibroblasts and the tumor cell lines CAL27, CAL33, XF354, BW-225, and GR-145-I/II, HK-147, BW-225, respectively. Data representing transcript expressions of CXCL1, 2, 3 are given in Fig. 2 a-c; data representing transcript expressions of CXCL10, 11, 9, 12 are given in Fig. 3 a-d. None of the analyzed cell lines expressed the chemokines CCL3, CCL4, and CCL19.

Of the receptors, transcript expression of CCR1, CCR2, CCR3, CCR5, CCR7, CCXR2, CCXR3 was not detected, and CCR6 expression was restricted to BHY, KOSC2, SKN3, GR-145-I, and HK-147 tumor cells (Fig. 4a). The CXC-chemokine receptors were expressed in different cell lines; CXCR1 was expressed in HaCat, CAL33, HSC4, and XF354 (Fig. 4b), and CXCR4 was expressed in HO 1u1, FaDu, BW-225, and ZMK-1 (Fig. 4c). Radiation caused up- and down-regulation with respect to chemokine expressions, while for chemokine receptor expressions down-regulations were prevailing. Greater than twofold radiation-related changes were regarded as significant and are marked by asterisks in the respective figures.

To test whether mRNA transcript expression was translated into protein, the presence of CXCL1 and CXCL12 was determined in cell culture supernatants by ELISA. Figure 5a, $\mathrm{b}$ show that the protein expression matches the mRNA transcript data well; however, no significant differences between irradiated and sham-irradiated cells were detected. Furthermore, Fig. 6 demonstrates that CXCL12 accumulates in irradiated cell culture supernatants over time, the increase being significant for tumor (BW-225) and normal (DF-19) cells.
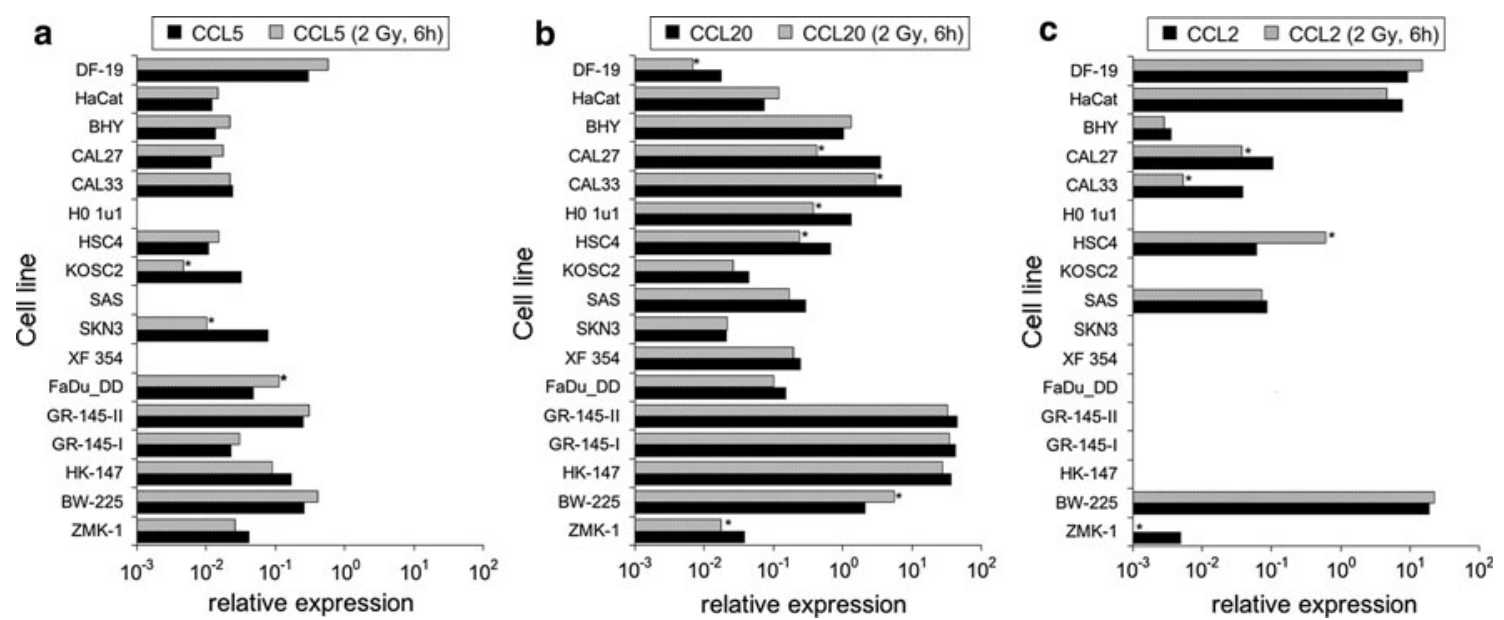

Fig. 1 CC-chemokine transcript expression relative to housekeeping genes in tumor and normal cell lines; a CCL5, b CCL20, c CCL2. Greater than twofold expression changes were regarded as significant and are marked by asterisks 

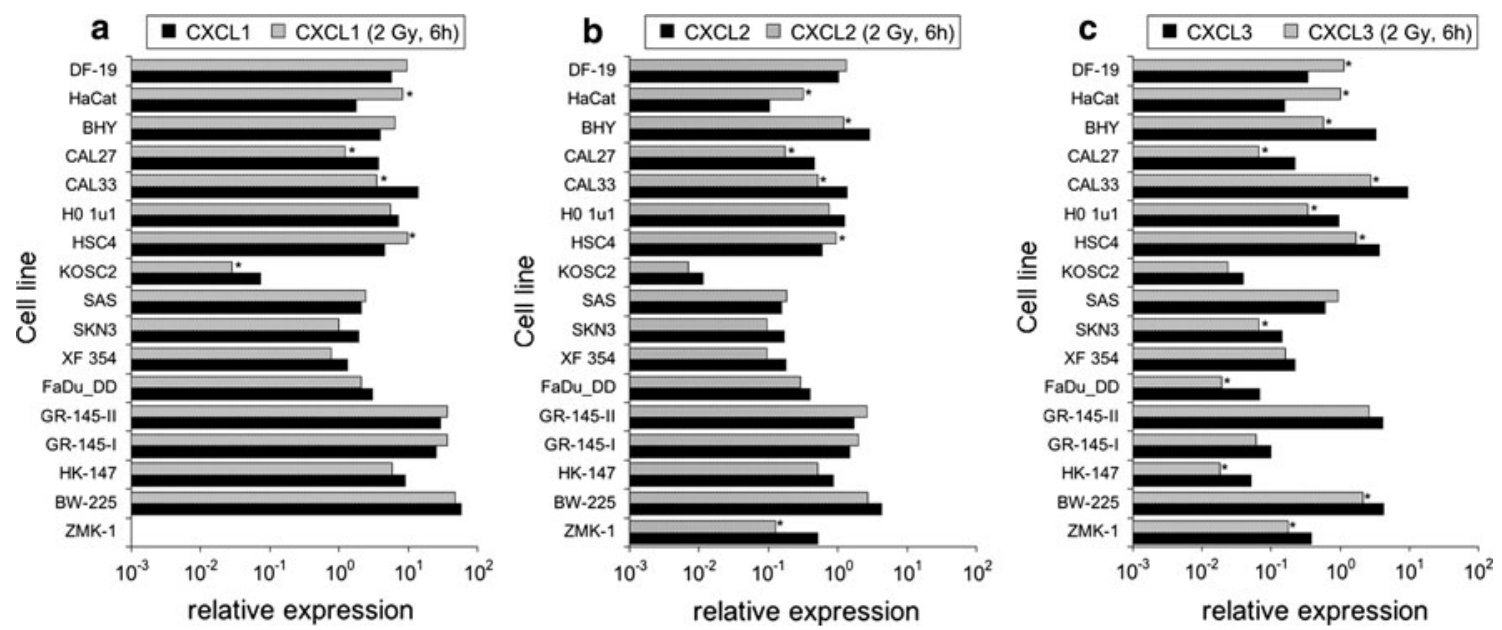

Fig. 2 CXC-chemokine transcript expression relative to housekeeping genes in tumor and normal cell lines; a CXCL1, b CXCL2, c CXCL3. Greater than twofold expression changes were regarded as significant and are marked by asterisks

\section{Discussion}

Aim of the present study was the analysis of chemokine and chemokine receptor expression in SCCHN tumor cell lines; for comparison, expressions in cell lines representing normal tissue were tested as well. All tumor cell lines represent squamous cell carcinoma (SSC), and all but one were derived from primary tumors. The only exception, XF 354 cells, stem from a lymph node metastasis of an oral SCC. Wang et al. showed a consistent pattern of CCR6 downregulation and up-regulation of CCR7 in metastatic SCCHN cells (Wang et al. 2005a); however, in the present study, neither CCR6 nor CCR7 expression was detected in XF 354 cells. This result is comparable to a study by Muller et al., reporting no difference in the expression of chemokine receptors in primary SCCHN and corresponding lymph node metastases (Muller et al. 2006).

In general, in the analyzed cell lines, the expression of chemokines was more common than the expression of chemokine receptors. The pronounced chemokine expression by the tumor cell lines may indicate that they reliably mirror the inflammatory microenvironment of tumors, although cultured cancer cells can exhibit distinct properties compared with their naturally growing counterparts. For SCCHN, the (over)-expression and secretion of the CC-chemokines CCL2, CCL5, and CCL20, which were identified in the cell lines of the present study, have repeatedly been described (Abiko et al. 2003; Buettner et al. 2007; Chang et al. 2008; Ferreira et al. 2008; Michiels et al. 2009). The same applies to the expression of the CXCchemokines, whereupon the homogeneous expression of CXC1-3 is explainable, as they cluster in a narrow region of chromosome 4 and are often coexpressed (Bieche et al. 2007). For SCCHN, CXC-chemokines have been suggested as useful as biomarkers for response and survival in patients with locally advanced oropharyngeal and head and neck SCC treated with radiochemotherapy (Allen et al. 2007).

Of the CXC receptors, only CXCR 1 and CXCR4 expression was detected in the analyzed tumor cell lines. Uchida et al. reported on comparable findings using lymph node metastatic (HNt and B88) and non-metastatic oral SCC cells, where of 13 kinds of chemokine receptors examined, only CXCR4 expression was up-regulated (Uchida et al. 2003). Several studies have already documented the importance of CXCR4 in SCCHN tumor progression and organspecific metastasis (Almofti et al. 2004; Delilbasi et al. 2004; Ishikawa et al. 2006; Oliveira-Neto et al. 2008; Rehman and Wang 2008; Tan et al. 2008) and that a high level of CXCR4 could be used as a prognostic factor (Wang et al. 2005c). Furthermore, it was suggested that in cases of oral SCC, the paracrine CXC12/CXCR4 system potentiates lymph node metastasis, but distant metastasis might require the autocrine CXC12/CXCR4 system (Uchida et al. 2007). Interestingly, of the tumor cell lines expressing CXCR4 in the present study, three (HO 1u1, FaDu, ZMK-1) expressed CXCR4 only, and one expressed CXCR4 and its ligand CXC12. The differential expression may render them possible candidates for cell migration and invasion studies after radiation or radiation and drug treatment.

For irradiation, the common clinical single dose of $2 \mathrm{~Gy}$ was used, as irradiation at therapeutic doses can induce essential molecular signals required for an effective response of the immune system to the tumor (Demaria and Formenti 2007). Even extremely low-dose ionizing radiation (1 cGy) caused an up-regulation of three CXC-chemokines (CXCL1, CXCL2, and CXCL6) in human fibroblasts (Fujimori et al. 2005). In the present study, the normal cells 
Fig. 3 CXC-chemokine transcript expression relative to housekeeping genes in tumor and normal cell lines;

a CXCL10, b CXCL11, c CXCL9, d CXCL12. Greater than twofold expression changes were regarded as significant and are marked by asterisks
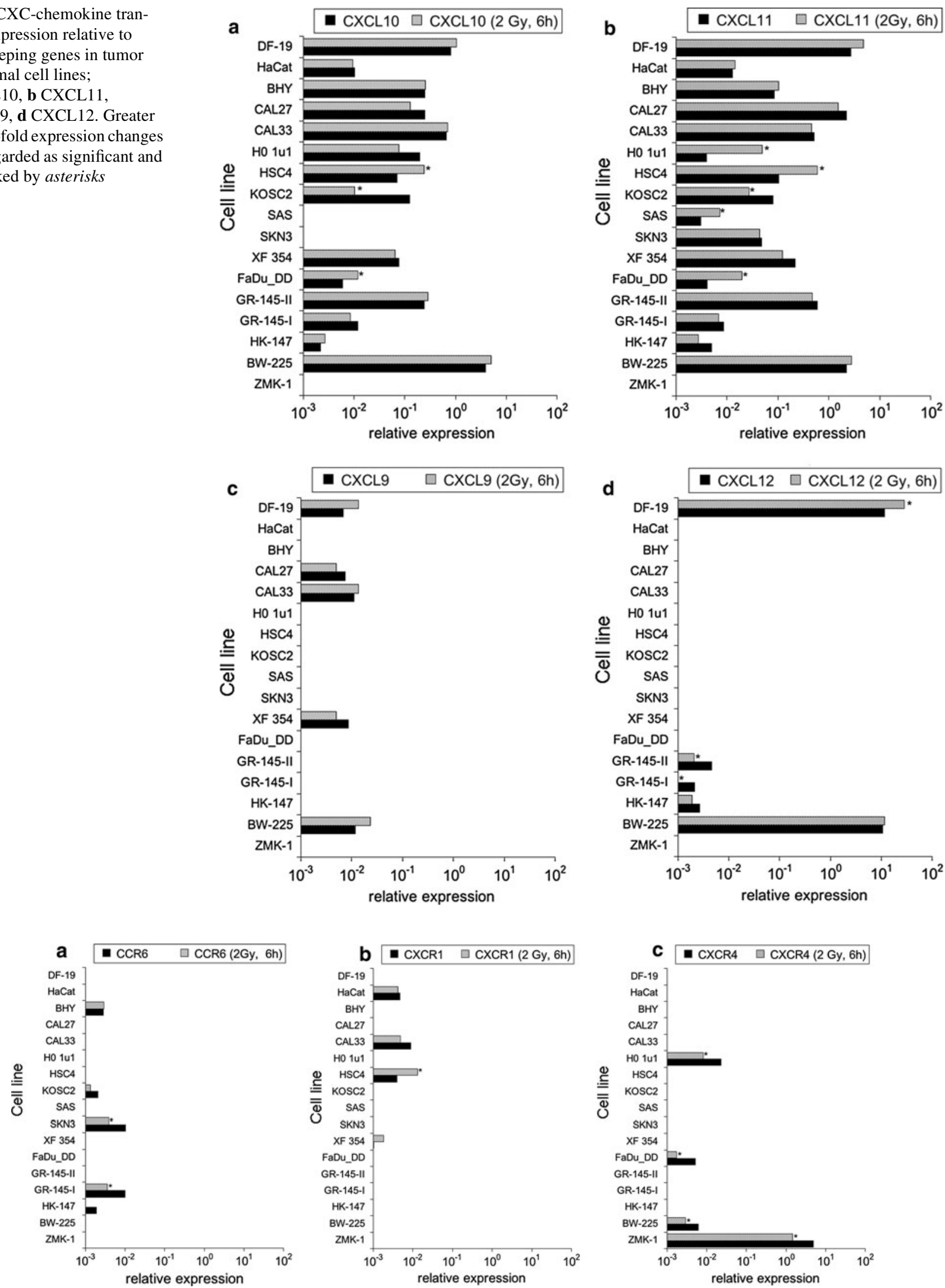

Fig. 4 Chemokine receptor transcript expression relative to housekeeping genes in tumor and normal cell lines; a CCR6, b CXCR1, c CXCR4. Greater than twofold expression changes were regarded as significant and are marked by asterisks 
Fig. 5 Protein expression in cell culture supernatants of tumor and normal cell lines; a CXCL1, b CXCL12

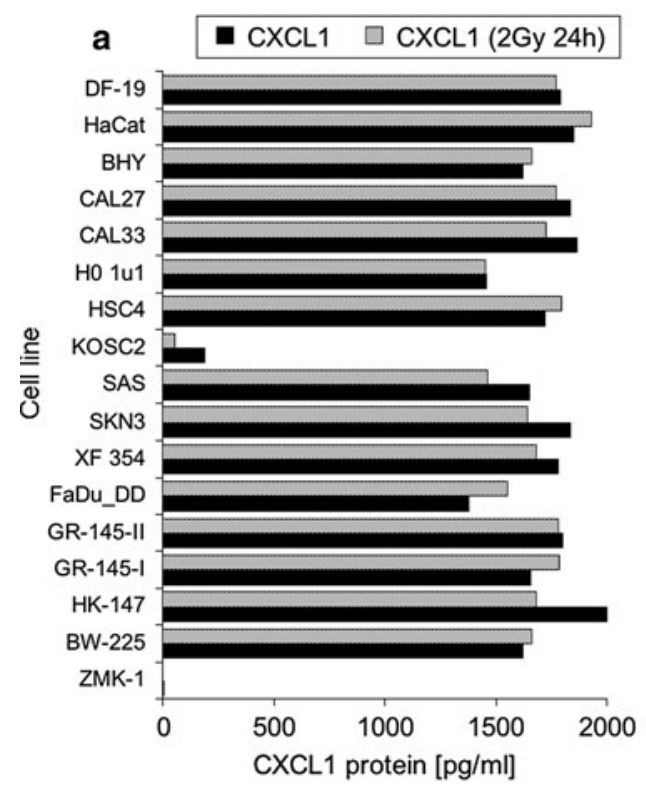

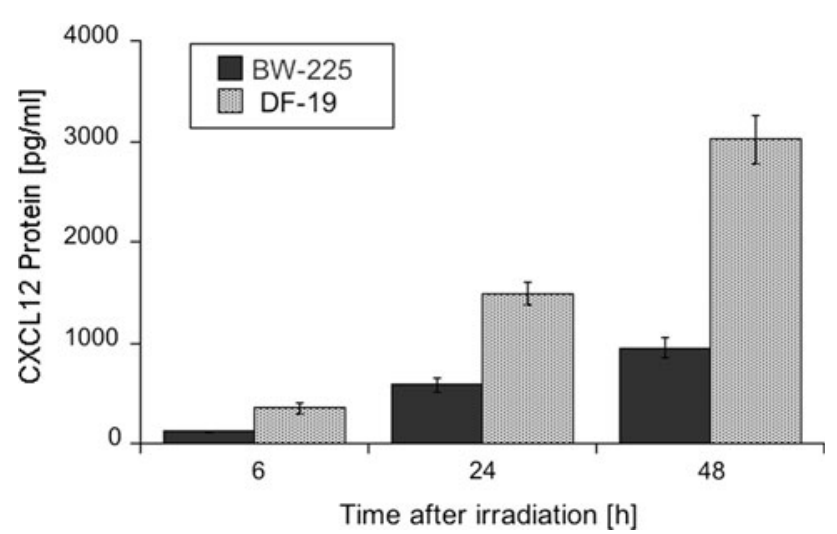

Fig. 6 CXCL12 protein expression in cell culture supernatants of BW-225 tumor and DF-19 normal cell lines 6, 24, and $48 \mathrm{~h}$ after irradiation. Data are normalized for CXCL12 content before irradiation; error bars represent standard errors of 3 measurements. The CXCL12 accumulation is statistically significant with $P=<0.001$

(fibroblasts; HaCat) also showed a radiation-induced up-regulation of CXCL1, CXCL2, and CXCL3, which was always greater than twofold in $\mathrm{HaCat}$ cells and greater than twofold for CXCL3 in fibroblasts. We could confirm the CXCL1 expression on the protein level; however, differences between irradiated and non-irradiated cells were marginal. With respect to the CXCL3 mRNA transcript expression, we observed a marked difference between normal and tumor cells; while both normal cell lines showed the above-mentioned radiation-induced up-regulation, a down-regulation was observed all tumor cell lines.

For further chemokines, e.g., the CC-chemokines CCL2 and CCL5, or the CXC-chemokine CXCL12, transcript expressions were modified after irradiation. It might be worth to test the possibility that chemokines could be used as biomarkers of radiation responses. For mice, it has already been shown that radiation induces earlier and greater temporal changes in multiple cytokines and chemokines in pulmonary fibrosis-sensitive compared to fibrosisresistant animals (Ao et al. 2009). Herein, we could show persistent expression and significant accumulation of CXCL12 protein in cell culture supernatants of irradiated tumor cells and fibroblasts.

Our study has several limitations. Although a wide panel of cell lines was used, the reported results cannot be generalized but apply solely to the cell lines of the present study. The transcript expressions reported herein and the detection of CXCL1 and CXCL12 proteins in cell culture supernatants are strong indicators of chemokine and chemokine receptor expressions, but will need confirmation by further protein analysis and functional assays in future.

In conclusion, the substantial variation in chemokine and chemokine receptor expression between SCCHN offer opportunities for the establishment of assays to test for the relevance of chemokine and chemokine receptor expression in the response of SCCHN to radiotherapy and radiochemotherapy.

Open Access This article is distributed under the terms of the Creative Commons Attribution Noncommercial License which permits any noncommercial use, distribution, and reproduction in any medium, provided the original author(s) and source are credited.

\section{References}

Abiko Y, Nishimura M, Kusano K, Nakashima K, Okumura K, Arakawa $T$ et al (2003) Expression of MIP-3alpha/CCL20, a macrophage inflammatory protein in oral squamous cell carcinoma. Arch Oral Biol 48(2):171-175 
Allen C, Duffy S, Teknos T, Islam M, Chen Z, Albert PS et al (2007) Nuclear factor-kappaB-related serum factors as longitudinal biomarkers of response and survival in advanced oropharyngeal carcinoma. Clin Cancer Res 13(11):3182-3190

Almofti A, Uchida D, Begum NM, Tomizuka Y, Iga H, Yoshida H et al (2004) The clinicopathological significance of the expression of CXCR4 protein in oral squamous cell carcinoma. Int J Oncol 25(1):65-71

Ao X, Zhao L, Davis MA, Lubman DM, Lawrence TS, Kong FM (2009) Radiation produces differential changes in cytokine profiles in radiation lung fibrosis sensitive and resistant mice. J Hematol Oncol 2:6

Bachmeier BE, Mohrenz IV, Mirisola V, Schleicher E, Romeo F, Hohneke $\mathrm{C}$ et al (2008) Curcumin downregulates the inflammatory cytokines CXCL1 and -2 in breast cancer cells via NFkappaB. Carcinogenesis 29(4):779-789

Bieche I, Chavey C, Andrieu C, Busson M, Vacher S, Le Corre L et al (2007) CXC chemokines located in the 4q21 region are up-regulated in breast cancer. Endocr Relat Cancer 14(4):1039-1052

Buettner M, Meyer B, Schreck S, Niedobitek G (2007) Expression of RANTES and MCP-1 in epithelial cells is regulated via LMP1 and CD40. Int J Cancer 121(12):2703-2710

Calcagno AM, Chewning KJ, Wu CP, Ambudkar SV (2006) Plasma membrane calcium ATPase (PMCA4): a housekeeper for RT-PCR relative quantification of polytopic membrane proteins. BMC Mol Biol 7:29

Chakraborty K, Bose A, Pal S, Chattopadhyay U, Baral R (2008) Interferon-alpha $2 b$ restores the impaired chemotactic activity of peripheral blood mononuclear cells from head and neck squamous cell carcinoma patients by modulating CXC receptor ligand interaction. J Interferon Cytokine Res 28(8):487-499

Chang KP, Hao SP, Chang JH, Wu CC, Tsang NM, Lee YS et al (2008) Macrophage inflammatory protein-3alpha is a novel serum marker for nasopharyngeal carcinoma detection and prediction of treatment outcomes. Clin Cancer Res 14(21):6979-6987

Cicinnati VR, Shen Q, Sotiropoulos GC, Radtke A, Gerken G, Beckebaum S (2008) Validation of putative reference genes for gene expression studies in human hepatocellular carcinoma using realtime quantitative RT-PCR. BMC Cancer 8:350

Delilbasi CB, Okura M, Iida S, Kogo M (2004) Investigation of CXCR4 in squamous cell carcinoma of the tongue. Oral Oncol 40(2):154-157

Demaria S, Formenti SC (2007) Sensors of ionizing radiation effects on the immunological microenvironment of cancer. Int J Radiat Biol 83(11-12):819-825

Deutsch AJ, Aigelsreiter A, Steinbauer E, Fruhwirth M, Kerl H, Beham-Schmid C et al (2008) Distinct signatures of B-cell homeostatic and activation-dependent chemokine receptors in the development and progression of extragastric MALT lymphomas. J Pathol 215(4):431-444

Facoetti A, Mariotti L, Ballarini F, Bertolotti A, Nano R, Pasi F et al (2009) Experimental and theoretical analysis of cytokine release for the study of radiation-induced bystander effect. Int J Radiat Biol 85(8):690-699

Ferreira FO, Ribeiro FL, Batista AC, Leles CR, de Cassia Goncalves Alencar R, Silva TA (2008) Association of CCL2 with lymph node metastasis and macrophage infiltration in oral cavity and lip squamous cell carcinoma. Tumour Biol 29(2):114-121

Fujimori A, Okayasu R, Ishihara H, Yoshida S, Eguchi-Kasai K, Nojima $\mathrm{K}$ et al (2005) Extremely low dose ionizing radiation up-regulates CXC chemokines in normal human fibroblasts. Cancer Res 65(22):10159-10163

Gremy O, Benderitter M, Linard C (2008) Acute and persisting Th2like immune response after fractionated colorectal gamma-irradiation. World J Gastroenterol 14(46):7075-7085
Ishikawa T, Nakashiro K, Hara S, Klosek SK, Li C, Shintani S et al (2006) CXCR4 expression is associated with lymph-node metastasis of oral squamous cell carcinoma. Int J Oncol 28(1):61-66

Johnston CJ, Williams JP, Okunieff P, Finkelstein JN (2002) Radiation-induced pulmonary fibrosis: examination of chemokine and chemokine receptor families. Radiat Res 157(3):256-265

Kato A, Chustz RT, Ogasawara T, Kulka M, Saito H, Schleimer RP et al (2009) Dexamethasone and FK506 inhibit expression of distinct subsets of chemokines in human mast cells. J Immunol 182(11):7233-7243

Khademi B, Razmkhah M, Erfani N, Gharagozloo M, Ghaderi A (2008) SDF-1 and CCR5 genes polymorphism in patients with head and neck cancer. Pathol Oncol Res 14(1):45-50

Kim TD, Li G, Song KS, Kim JM, Kim JS, Yun EJ et al (2009) Radiation-induced thymidine phosphorylase upregulation in rectal cancer is mediated by tumor-associated macrophages by monocyte chemoattractant protein-1 from cancer cells. Int J Radiat Oncol Biol Phys 73(3):853-860

Kuhlmann UC, Chwieralski CE, Reinhold D, Welte T, Buhling F (2009) Radiation-induced matrix production of lung fibroblasts is regulated by interleukin-8. Int J Radiat Biol 85(2):138-143

Linard C, Marquette C, Mathieu J, Pennequin A, Clarencon D, Mathe D (2004) Acute induction of inflammatory cytokine expression after gamma-irradiation in the rat: effect of an NF-kappaB inhibitor. Int J Radiat Oncol Biol Phys 58(2):427-434

Lugade AA, Sorensen EW, Gerber SA, Moran JP, Frelinger JG, Lord EM (2008) Radiation-induced IFN-gamma production within the tumor microenvironment influences antitumor immunity. J Immunol 180(5):3132-3139

Malik IA, Moriconi F, Sheikh N, Naz N, Khan S, Dudas J et al (2010) Single-dose gamma-irradiation induces up-regulation of chemokine gene expression and recruitment of granulocytes into the portal area but not into other regions of rat hepatic tissue. Am J Pathol 176(4):1801-1815

Matsumura S, Wang B, Kawashima N, Braunstein S, Badura M, Cameron TO et al (2008) Radiation-induced CXCL16 release by breast cancer cells attracts effector $\mathrm{T}$ cells. J Immunol 181(5):3099-3107

Michiels K, Schutyser E, Conings R, Lenaerts JP, Put W, Nuyts S et al (2009) Carcinoma cell-derived chemokines and their presence in oral fluid. Eur J Oral Sci 117(4):362-368

Mihaescu A, Santen S, Jeppsson B, Thorlacius H (2010) p38 Mitogenactivated protein kinase signalling regulates vascular inflammation and epithelial barrier dysfunction in an experimental model of radiation-induced colitis. Br J Surg 97(2):226-234

Miyazaki H, Patel V, Wang H, Edmunds RK, Gutkind JS, Yeudall WA (2006) Down-regulation of CXCL5 inhibits squamous carcinogenesis. Cancer Res 66(8):4279-4284

Moriconi F, Christiansen H, Raddatz D, Dudas J, Hermann RM, Rave-Frank M et al (2008) Effect of radiation on gene expression of rat liver chemokines: in vivo and in vitro studies. Radiat Res 169(2):162-169

Muller K, Meineke V (2007) Radiation-induced alterations in cytokine production by skin cells. Exp Hematol 35(4 Suppl 1):96-104

Muller A, Sonkoly E, Eulert C, Gerber PA, Kubitza R, Schirlau K et al (2006) Chemokine receptors in head and neck cancer: association with metastatic spread and regulation during chemotherapy. Int $\mathrm{J}$ Cancer 118(9):2147-2157

Okamoto Y, Folco EJ, Minami M, Wara AK, Feinberg MW, Sukhova GK et al (2008) Adiponectin inhibits the production of CXC receptor 3 chemokine ligands in macrophages and reduces T-lymphocyte recruitment in atherogenesis. Circ Res 102(2): 218-225

Oliveira-Neto HH, Silva ET, Leles CR, Mendonca EF, Alencar Rde C, Silva TA et al (2008) Involvement of CXCL12 and CXCR4 in 
lymph node metastases and development of oral squamous cell carcinomas. Tumour Biol 29(4):262-271

Rave-Frank M, Virsik-Peuckert P, Bertram K, Schmidberger H (1996) Chromosome analysis in X-irradiated primary cells of a human squamous cell carcinoma by fluorescence in situ hybridization. Int J Radiat Biol 69(6):695-700

Rehman AO, Wang CY (2008) SDF-1alpha promotes invasion of head and neck squamous cell carcinoma by activating NF-kappaB. J Biol Chem 283(29):19888-19894

Samara GJ, Lawrence DM, Chiarelli CJ, Valentino MD, Lyubsky S, Zucker S et al (2004) CXCR4-mediated adhesion and MMP-9 secretion in head and neck squamous cell carcinoma. Cancer Lett 214(2):231-241

Sanzari JK, Nuth M, Kennedy AR (2009) Induction of cytokine gene expression in human thyroid epithelial cells irradiated with HZE particles (iron ions). Radiat Res 172(4):437-443

Schmidtner J, Distel LV, Ott OJ, Nkenke E, Sprung CN, Fietkau R et al (2009) Hyperthermia and irradiation of head and neck squamous cancer cells causes migratory profile changes of tumour infiltrating lymphocytes. Int J Hyperthermia 25(5):347-354

Takes RP, Rinaldo A, Rodrigo JP, Devaney KO, Fagan JJ, Ferlito A (2008) Can biomarkers play a role in the decision about treatment of the clinically negative neck in patients with head and neck cancer? Head Neck 30(4):525-538

Tan CT, Chu CY, Lu YC, Chang CC, Lin BR, Wu HH et al (2008) CXCL12/CXCR4 promotes laryngeal and hypopharyngeal squamous cell carcinoma metastasis through MMP-13-dependent invasion via the ERK1/2/AP-1 pathway. Carcinogenesis 29(8): 1519-1527

Tsuzuki H, Takahashi N, Kojima A, Narita N, Sunaga H, Takabayashi $\mathrm{T}$ et al (2006) Oral and oropharyngeal squamous cell carcinomas expressing CCR7 have poor prognoses. Auris Nasus Larynx 33(1):37-42

Uchida D, Begum NM, Almofti A, Nakashiro K, Kawamata H, Tateishi Y et al (2003) Possible role of stromal-cell-derived factor-1/CXCR4 signaling on lymph node metastasis of oral squamous cell carcinoma. Exp Cell Res 290(2):289-302

Uchida D, Onoue T, Tomizuka Y, Begum NM, Miwa Y, Yoshida H et al (2007) Involvement of an autocrine stromal cell derived factor-1/CXCR4 system on the distant metastasis of human oral squamous cell carcinoma. Mol Cancer Res 5(7):685-694
Ueda M, Shimada T, Goto Y, Tei K, Nakai S, Hisa Y et al (2009) Expression of CC-chemokine receptor 7 (CCR7) and CXCchemokine receptor 4 (CXCR4) in head and neck squamous cell carcinoma. Auris Nasus Larynx 37(4):488-495

Wang J, Xi L, Hunt JL, Gooding W, Whiteside TL, Chen Z et al (2004) Expression pattern of chemokine receptor 6 (CCR6) and CCR7 in squamous cell carcinoma of the head and neck identifies a novel metastatic phenotype. Cancer Res 64(5):1861-1866

Wang J, Xi L, Gooding W, Godfrey TE, Ferris RL (2005a) Chemokine receptors 6 and 7 identify a metastatic expression pattern in squamous cell carcinoma of the head and neck. Adv Otorhinolaryngol 62:121-133

Wang J, Zhang X, Thomas SM, Grandis JR, Wells A, Chen ZG et al (2005b) Chemokine receptor 7 activates phosphoinositide-3 kinase-mediated invasive and prosurvival pathways in head and neck cancer cells independent of EGFR. Oncogene 24(38): 5897-5904

Wang N, Wu QL, Fang Y, Mai HQ, Zeng MS, Shen GP et al (2005c) Expression of chemokine receptor CXCR4 in nasopharyngeal carcinoma: pattern of expression and correlation with clinical outcome. J Transl Med 3:26

Wang J, Seethala RR, Zhang Q, Gooding W, van Waes C, Hasegawa $\mathrm{H}$ et al (2008) Autocrine and paracrine chemokine receptor 7 activation in head and neck cancer: implications for therapy. J Natl Cancer Inst 100(7):502-512

Wang F, Arun P, Friedman J, Chen Z, Van Waes C (2009) Current and potential inflammation targeted therapies in head and neck cancer. Curr Opin Pharmacol 9(4):389-395

Wen DS, Zhu XL, Guan SM, Wu YM, Yu LL, Wu JZ (2008) Silencing of CXCR4 inhibits the proliferation, adhesion, chemotaxis and invasion of salivary gland mucoepidermoid carcinoma Mc 3 cells in vitro. Oral Oncol 44(6):545-554

Yeudall WA, Miyazaki H (2007) Chemokines and squamous cancer of the head and neck: targets for therapeutic intervention? Expert Rev Anticancer Ther 7(3):351-360

Zhou W, Jiang Z, Song X, Liu Y, Wen P, Guo Y et al (2008) Promoter hypermethylation-mediated down-regulation of CXCL12 in human astrocytoma. J Neurosci Res 86(13):3002-3010

Zlotnik A (2006) Chemokines and cancer. Int J Cancer 119(9):2026-2029 